Tropical Journal of Pharmaceutical Research December 2010; 9 (6): 565-572

(C) Pharmacotherapy Group,

Faculty of Pharmacy, University of Benin

Benin City, 300001 Nigeria.

All rights reserved.

Research Article

Available online at http://www.tjpr.org

\title{
PFCRT and DHFR-TS Sequences for Monitoring Drug Resistance in Adzopé Area of Côte d'Ivoire After the Withdrawal of Chloroquine and Pyrimethamine
}

\author{
L Ouattara ${ }^{1}$, KB Bla ${ }^{1}$, SB Assi ${ }^{2}$, W Yavo ${ }^{1,2}$ and AJ Djaman ${ }^{1,3^{*}}$ \\ ${ }^{1}$ UFR Biosciences et UFR des Sciences Pharmaceutiques \& Biologiques, Université de Cocody, BP V34 Abidjan, \\ ${ }^{2}$ Institut Pierre Richet de Bouaké /Institut National de Santé Publique, BP V47 Abidjan, ${ }^{3}$ Institut Pasteur de Côte \\ d'Ivoire, 01 BP 490 Abidjan 01, Côte d'Ivoire
}

\begin{abstract}
Purpose: Drug resistance is probably the greatest challenge to most malaria-control programmes. The goal of this study was to evaluate polymorphisms in parasite resistance gene markers, pfcft and dhfr, from falciparum malaria isolates collected in Adzopé City, Côte d'Ivoire in 2007.

Methods: Blood samples were collected in filter paper from 72 children infected with Plasmodium falciparum living in Adzopé area. Plasmodium falciparum DNA was extracted and nested PCRs were performed using specific primers of pfcrt and dhfr-ts. During the study, chloroquine and sulphadoxinepyrimethamine (which previously were the first- and second-line treatments, respectively, for malaria in Côte d'Ivoire) were not given to the enrolled children, having been withdrawn in 2004.

Results: The results revealed the presence of the mutant-type pfort and dhfr-ts in 51 (62.2\%) and 29 (35.4\%) samples, respectively. The mutant-type pfort alleles consisted of four single mutations (Met74/Asn75/Thr76) and 47 triple mutations (Ile74/Glu75/Thr76). However, the frequency distribution of mutations in dhfr-ts was $35.4 \%$ for dhfr-Asn 108, $17 \%$ for dhfr-lle51 and $21 \%$ for dhfr-Arg59.

Conclusion: The results of this study show high presence of chloroquine (CQ) resistance markers while for sulphadoxine-pyrimethamine (SP), a much lower prevalence was detected for the markers under study. Chloroquine remains an inadequate drug for malaria therapy in the study region. Furthermore, in spite of the official withdrawal of $C Q$ and SP in favour of the arteminisin-based combinations (ACTs), it appears the population of this area continues to use the drugs via self-medication.
\end{abstract}

Keywords: Côte d'Ivoire, Plasmodium falciparum, Malaria resistance, Molecular markers 


\section{INTRODUCTION}

Malaria remains a major cause of morbidity and mortality in sub-Saharan Africa [1]. Worldwide malaria morbidity is estimated to be 300-500 million cases with about 1 million deaths each year, of which $90 \%$ occur in subSaharan Africa [2]. The vast majority of deaths occur among children below five years of age and pregnant women, especially in remote rural areas with poor access to health services [3].

Malaria control is hampered by increasing spread of drug resistance. Although sulphadoxine-pyrimethamine (SP) has been abandoned as first- or second-line treatments, respectively, by most African malaria endemic countries in favour of artemisinin-based combination treatments $(A C T)$, it is still used as intermittent preventive treatment during pregnancy (IPTp) [4]. However, SP resistance has been on the rise in the past few years and, although the link between molecular markers and treatment failure has not been firmly established, at least for pregnant women, these markers should be monitored. Pyrimethamine inhibits dihydrofolate reductase (DHFR), whereas sulfadoxine inhibits dihydropteroate synthetase (DHPS) [5].

Resistance to these drugs has been associated with single nucleotide polymorphisms (SNP) in the genes encoding DHFR and DHPS [6]. The key amino acid substitutions that confer falciparum malaria resistance to sulfadoxine and pyrimethamine are Ala437Gly and Lys540Glu or Ala437Gly in dihydropteroate synthase (DHPS), and Ser108Asn or Ser108Thr in dihydrofolate reductase (DHFR). In addition, dhfr mutations from Asn-51 to Ile-51 and Cys-59 to Arg-59 in association with Asn-108 were found to be associated with greater resistance to pyrimethamine [7].

In most countries, chloroquine (CQ) was, for many years, the first-line drug for malaria treatment. Unfortunately, resistance to this drug is nowadays widespread. However, in areas where drug pressure has been removed, the molecular markers linked to $C Q$ drug resistance seem to disappear, indicating that local parasites are again sensitive to this drug $[8,9]$.

It is, therefore, important to use molecular markers for monitoring drug resistance in a country and understand its spread as this may be important in designing strategies to guide the selection of drug resistant parasites. The spread of point mutations linked to drug resistance could be monitored by carrying out regular cross sectional surveys and then genotyping the samples from infected people. Molecular tools for the detection and identification of these SNPs, such as restriction fragment length polymorphism PCR (RFLP-PCR), are available [10]. CQ resistance is associated with a mutation in the Plasmodium falciparum chloroquine resistance transporter gene (K76T) [11]. This mutation is generally not isolated but is associated, depending on the geographical setting, with mutations at other codons, Cys72Ser, Met74lle, Asn75Glu, Ala220Ser, Gln271Glu, Asn326Ser, Ile356Thr and Arg371lle, the role of which is not well defined.

In Côte d'Ivoire, until 2003, CQ and SP were used as first- and second-line drugs, respectively, for the treatment of uncomplicated malaria. ACT replaced $C Q$ as the recommended first-line drug. SP remains recommended for IPT among pregnant women. A few years after, it was considered important to measure the prevalence of molecular markers of chloroquine and pyrimethamine resistance. Indeed, in Malawi, a sub-Saharan country, from 1992 to 2000, the prevalence of the $\mathrm{CQ}$ marker gradually decreased, disappearing completely by 2001 after the withdrawal of $\mathrm{CQ}$ [12].

The study aimed to evaluate $S P$ and $C Q$ resistance in falciparum malaria isolates, following withdrawal of these drugs, in 
Adzopé, Côte d'lvoire, using molecular characterization of the dhfr-ts and pfcrt genes, respectively. This city is considered as one of the sentinel sites of the national programme for malaria control.

\section{EXPERIMENTAL}

\section{Blood collection area}

This study is a part of the cross-sectional surveys carried out in 2007 in Adzopé (lat. $06^{\circ} 06^{\prime} \mathrm{N}$ and long. $03^{\circ} 51^{\prime} \mathrm{W}$ ), situated in the south of Côte d'Ivoire, $108 \mathrm{~km}$ from Abidjan, the economic capital city. The rainy season occurs from March to July (average rainfall: $1,789 \mathrm{~mm} / \mathrm{yr}$ ). The population was estimated at 43,821 inhabitants in 1998. Malaria is hyperendemic with no seasonal transmission. The most common vectors are Anopheles gambiae and Culex Quinquefasciatus. Plasmodium falciparum is the predominant malaria parasite.

Blood samples used in this study were collected at random from 72 children aged between 6 months and 14 years, during a cross sectional survey in Adzopé. Fingerprick samples of capillary blood were collected from the selected children onto a filter paper strip (Isocode Stix®; Schleichler and Schuell, Ecquevilly, France). The samples were dried and stored at room temperature in an individual zip-lock polyethylene bags prior to DNA extraction and PCR studies.

\section{Plasmodium DNA extraction and amplification}

DNA was extracted from the dried blood on each filter-paper strip by rinsing each strip with $500 \mu \mathrm{L}$ distilled water, immersing it in 75 $\mu \mathrm{L}$ distilled water in a $0.5 \mathrm{~mL}$ microtube and then incubating at $99{ }^{\circ} \mathrm{C}$ for $30 \mathrm{~min}$ [13].

The following mixture was prepared to a final volume of $50 \mu \mathrm{L}$ : genomic DNA extracted as described above, 10 picomoles of each specific primer (obtained from SigmaAldrich $\AA$ ), buffer (10 mM Tris, pH 8.3, $50 \mathrm{mM}$
$\left.\mathrm{KCl}, \quad 1.5 \mathrm{mM} \quad \mathrm{MgCl}_{2}\right), \quad 0.2 \mathrm{mM}$ of deoxynucleoside triphosphates (mixture of dGTP, dATP, dTTP, and dCTP), and one unit of taq DNA polymerase (Roche Diagnostics, Meylan, France).

For the primary PCR, the primers pairs used were STIL (5'ATG-ATG-GAA-CAA-GTCTGC-GAC-GTT-TTC-GAT)/ST2L(5'TTC-ATTTAA-CAT-TTT-ATT-ATT-CGT-TTT-CTT) for dhfr-ts and TCRP-1 (5'CCG-TTA-ATA-ATAAAT-ACA-CGC-AG) /TCRP-2 (5'CGG-ATGTTA-CAA-AAC-TAT-AGT-TAC-C) for pfcrt. Due to the small quantity of DNA imbibed onto filter paper, nested PCR was necessary to obtain sufficient amount of amplified products for direct PCR sequencing or PCRRFLP. So, the first amplification was performed as described above, using $12.5 \mu \mathrm{L}$ of DNA suspension. The secondary amplification was performed on the primary amplification product with internal primers: ST1L/DHFR-595R (5'CTG-GAA-AAA-ATACAT-CAC-ATT-CAT-ATG-TAC) for dhfr-ts (595bp fragment) and TCDR-1 (5'TGT-GCTCAT-GTG-TTT-AAA-CTT) /TCDR-2 (5'CAAAAC-TAT-AGT-TAC-CAA-TTT-TG) for pfcrt (145 pb fragment). For the all running PCRs, the PTC-100 thermal cycler (MJ Research, Watertown, MA, USA) was programmed to carry out 30 cycles of $94{ }^{\circ} \mathrm{C}$ for 2 min (first cycle) or $1 \mathrm{~min}$ (rest of the cycle), $50^{\circ} \mathrm{C} \times 1$ min $\left(56 \times 30 \mathrm{~s}\right.$ for pfcrt), and $72{ }^{\circ} \mathrm{C} \times 1 \mathrm{~min}$, followed by $72{ }^{\circ} \mathrm{C} \times 10 \mathrm{~min}$ at the end of 30 cycles.

\section{PCR-RFLP and sequencing of DNA fragments}

Pfcrt PCR products were digested by $A p o \mathrm{I}$ at $50^{\circ} \mathrm{C}$ in the presence of NE buffer $3(50 \mathrm{mM}$ Tris- $\mathrm{HCl}, 10 \mathrm{mM} \mathrm{MgCl}, 100 \mathrm{mM} \mathrm{NaCl}, 1 \mathrm{mM}$ DDT). As for dhfr-ts PCR products, they were submitted to the digestion of Alu I $\left\{\left(37^{\circ} \mathrm{C}, \mathrm{NE}\right.\right.$ buffer 2 (10mM Tris- $\mathrm{HCl}, 10 \mathrm{mM} \mathrm{MgCl}_{2}$, $50 \mathrm{mM} \mathrm{NaCl}$ and $1 \mathrm{mM} \mathrm{DTT})\}$. Apo I and Alu I cut the wild DNA fragments, haplotype Lys76 and Ser-108 of pfcrt and dhfr-ts genes, respectively.

Trop J Pharm Res, December 2010; 9(6):567 
However, in spite of the use of these enzymes, all the PCR products or DNA fragments from agarose gel (mixed alleles) were purified using the High Pure Kit purification product (Roche Diagnosis) and then sequenced in order to investigate additional mutations.

\section{Quality control and Data analysis}

A known DNA of $P$. falciparum was used as positive control in the PCR evaluation. The electropherograms of the purification PCR products sequenced by MWG-biotech (MWGEurofin Operon) were analyzed by using 4 peaks, Chromas Lite version 2.01 and ApE-A plasmid Editor V1.12 software.

According to the haplotypes 74,75 and 76 of pfcrt gene investigated, the wild-type pfcrt isolate was defined by the following combination: Met74/Asn75/Lys76, while for dhfr-ts, the allelic combination Ala16/Asn51/Cys59/Ser108/l164 defined the wild-type isolates. However, for each gene, the key amino-acid mutations that confer the resistance are Lys76 for pfcrt and Ser108 for dhfr-ts, respectively.

\section{Ethical review}

The study protocol was approved by the ethics committee of the Ivorian Ministry of Public Health and all legal parents or guardians of enrolled children gave their consent for blood sampling.

\section{RESULTS}

A total of 72 samples collected were successfully amplified. After PCR-RFLP running, according to only the haplotype 76 of pfcrt, 21 (29\%) wild type pfcrt Lys76, 41 (57 $\%)$ mutant type pfort Thr76 and 10 (14\%), mixed population wild type/mutant type DNA fragments were obtained. For dhfr-ts, the outcome confirmed again the presence of 10 wild type/mutant type (Ser108Asn) dhfr-ts isolates against 19 mutant-type dhfr-ts Asn108 (Table 1).
Table 1: Distribution of DNA samples according to genetic profile

\begin{tabular}{|c|c|c|}
\hline \multirow[b]{2}{*}{$\begin{array}{l}\text { Molecular } \\
\text { marker }\end{array}$} & \multicolumn{2}{|c|}{ Genotype and no. of samples } \\
\hline & $\begin{array}{l}\text { PCR-RFLP } \\
(n=72)\end{array}$ & $\begin{array}{l}\text { DNA } \\
\text { sequencing } \\
(n=82)\end{array}$ \\
\hline \multirow{5}{*}{ PFCRT } & Wild-type (21) & Wild-type (31) \\
\hline & $\begin{array}{l}\text { Mutant-type } \\
(41)\end{array}$ & $\begin{array}{l}\text { Mutant-type } \\
\text { (51) }\end{array}$ \\
\hline & $\begin{array}{l}\text { Wild- } \\
\text { type/Mutant- } \\
\text { type (10) }\end{array}$ & sM (4) \\
\hline & & $\mathrm{dM}(0)$ \\
\hline & & $\mathrm{tM}(47)$ \\
\hline \multirow{6}{*}{ DHFR-TS } & Wild-type (43) & "Wild-type (53) \\
\hline & Mutant-type & Mutant-type \\
\hline & $(19)$ & (29) \\
\hline & $\begin{array}{l}\text { Wild- } \\
\text { type/Mutant- } \\
\text { type (10) }\end{array}$ & sM (4) \\
\hline & & $\mathrm{dM}(19)$ \\
\hline & & $\mathrm{tM}(6)$ \\
\hline
\end{tabular}

"- sM (single mutation): Thr76 for PFCRT and Asn108 for DHFR-TS

- dM (double mutation): no double mutation was found in PFCRT; Ile51/Asn108 and Arg59/Asn108 in DHFR

- tM (triple mutation): Ile74/Glu75/Thr76 in PFCRT and, Ile51/Arg59/Asn108 in DHFR-TS

Due to the presence of the 10 mixed alleles, a total of 82 DNA fragments were sequenced instead of 72 . Among them, 31 (37.8\%) were wild-type pfcrt (Met74/Asn75/Lys76) against $51(62.2 \%)$ mutant type pfcrt. The mutant pfort haplotypes consisted of four single mutations (Met74/Asn75/Thr76) and 47 triples mutations (Ile74/Glu75/Thr76). No double mutations were found (Table 1). The distribution of each PFCRT allele was: 57.3 $\%$ (47) for both Ile74 Glu75, while 51 (62.2 $\%)$ samples of DNA fragments were Thr76 mutations (Table 2, Figure 1).

Of the 82 samples of $P$. falciparum isolates investigated, $53(64.6 \%)$ had wild-type dhfrts, while 29 (35.4\%) were mutant-type dhfrts. They consisted of four single mutant-type samples (Asn51/Cys59/Asn108), nineteen double mutations distributed as follows: lle51/Cys59/Asn108 (eight) and Asn51/Arg59/Asn108 (eleven). Six samples were triple mutant-type dhfr-ts lle51/Arg59/Asn108 mutation (Table 2). 
Table 2: Amino-acid residues obtained in DNA fragments in PFCRT and Plasmodium falciparum samples

\begin{tabular}{ccc}
\hline \multicolumn{3}{c}{ Amino-acids residues obtained and } \\
corresponding samples of $\boldsymbol{P}$. falciparum \\
\hline \multicolumn{1}{c}{ PFCRT* } & DHFR-TS & No. of samples \\
$\mathbf{7 4} \mathbf{7 5} \mathbf{7 6}$ & $\mathbf{5 1} \mathbf{5 9} \mathbf{1 0 8}$ & \\
\hline MNK & NCS & 23 \\
MNK & NRN & 2 \\
MNK & ICN & 2 \\
MNK & IRN & 4 \\
MNT & NRN & 2 \\
MNT & IRN & 2 \\
IET & NCS & 30 \\
IET & NCN & 4 \\
IET & NRN & 7 \\
IET & ICN & 6 \\
\hline${ }^{*}$ The amino-acids residues transferred at different \\
positions in PFCRT and DHFR-TS alleles are \\
highlighted. For DHFR-TS, the haplotypes 16 and 164 \\
were wild-type in all samples
\end{tabular}

Haplotypes 16 and 164 of the dhfr-ts in all DNA fragments were of the wild type. Any Thr108 allele in DHFR-TS was not detected in DNA fragments analyzed. The frequency distribution of the point mutations in dhfr among the mutant samples detected in the present study is shown in Figure 1.

Among the 82 samples analysed in the study, $59(72 \%)$ were affected by at least one point mutation in pfcrt and/or dhfr-ts genes (Table 2).

\section{DISCUSSION}

Drug resistance is probably the greatest challenge to most malaria control programmes. Given the limited resources for other malaria control measures, rational drug use is crucial, although economic constraints and the scarcity of the drug of choice hampers this. Close monitoring of the epidemiology and dynamics of drug resistance are necessary to implement measures to circumvent the problem and to allow Côte d'Ivoire's National Malaria Control Programme to recommend the best available management of malaria.

Like the in vitro tests, molecular markers of resistance might provide an early warning system in geographical or temporal monitor-

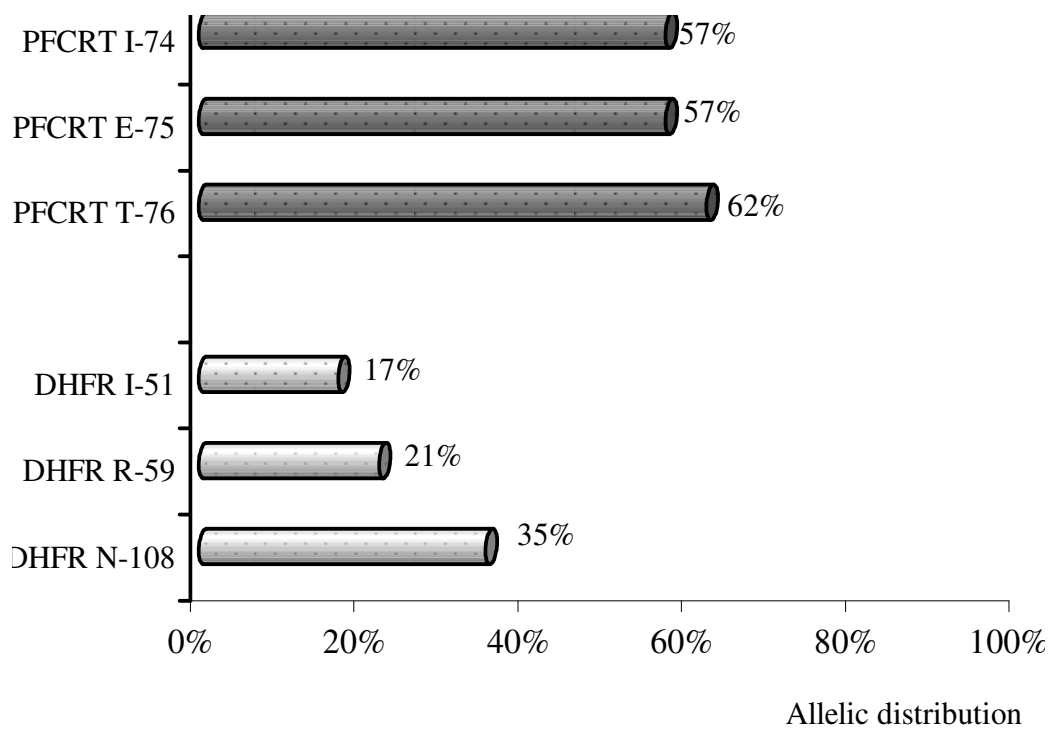

Figure 1: Frequency distribution of key amino acids found in PFCRT and DHFR among the Plasmodium falciparum isolates in the area of Adzopé, Côte d'Ivoire 
ing for guiding treatment efficacy studies [14]. Molecular markers are useful for monitoring the prevalence of mutations after a drug has been withdrawn or when a drug combination is used [12]. Our study was focused on molecular markers for chloroquine and pyrimethamine resistance.

This study reveals a high frequency of drug resistance molecular markers for $\mathrm{CQ}$ (pfcrt Thr76; 62.2\%). A similar study carried out in Abidjan, an area near Adzopé, reported $65 \%$ of mutant type pfcrt Thr76 [15]. Previous studies conducted in Côte d'lvoire and elsewhere in West Africa showed strong relationship between pfcrt Thr76 and therapeutic failure or in vitro chemoresistance of Plasmodium falciparum isolates to chloroquine $[16,17]$. This mutation is not generally isolated but is associated with other mutations at haplotypes $72,74,75$, etc. In this study, most of the mutant-type pfort were triple mutant (Ile74/Glu75/Thr76) but the role of these complementary mutations is not well defined. A few years later, chloroquine was withdrawn from use due to high treatment failure rates (> $44 \%)$. The proportion of pfcrt mutation $(62 \%)$ is reasonable evidence that there is a high level of chloroquine-resistant parasites circulating in this area. Thus, it would be too early to consider returning to the use of chloroquine alone as an antimalarial, although the drug itself is a safe and inexpensive, and ideally may be used in combination with another suitable antimalarial drug. In contrast, in Malawi, the first African country to replace chloroquine with SP, from 1992 to 2000, the prevalence of the molecular marker of chloroquine gradually decreased, disappearing completely by 2001 [12]. Today, chloroquine is once again highly efficacious in Malawi, 12 years after cessation of chloroquine use in that country [8].

For dhfr-ts gene, the mutation mainly affected codons 108 (35\%), 59 (21\%) and 51(17\%). Quadruple mutant, implying also the haplotype 16 or 164 which represents the most severe form of resistance and is responsible for high level of resistance to pyrimethamine, is at the present time not among the isolates of Côte d'Ivoire. These results are in agreement with others from western Africa, where prevalence of quadruple mutant has been observed [18]. A few rare strains carry the quadruple mutations in Africa, namely, Ghana, Kenya and Tanzania $[19,20]$. Elsewhere in the world, the $\|$ le164Leu mutation is relatively uncommon but has been reported in Bangladesh, Bolivia, Brazil, Cambodia, China, India, Malaysia, Peru, Thailand and Viet Nam [21,22].

Although the frequency of mutation of $d h f r-t s$ (Asn108, 35.4\%) is relatively less than that seen with $C Q$ in the same area (62.2\%), it is still alarming considering that the use of sulphadoxine-pyrimethamine as intermittent preventive treatment in pregnancy is unavoidable because suitable alternatives are not available yet. However, the prevalence of molecular markers of malarial organisms resistant to both chloroquine and pyrimethamine represented $48.8 \%$ of the total samples. One of the reasons for this high level of the molecular markers of $C Q$ and SP resistance is probably the wide usage of these drugs in Côte d'Ivoire in spite of their official replacement with ACT for the treatment of uncomplicated falciparum malaria. Maybe it is too early to evaluate the sensitivity of these drugs by monitoring the molecular markers for falciparum malaria resistance. In that case, it would be necessary to wait for some years before embarking on another study of this type.

\section{CONCLUSION}

The study was the first molecular study carried out in this geographical area which is considered as one of the sentinel sites for malaria control programme of Côte d'ivoire. The results of the epidemiological study on the prevalence of genotypes associated with drug resistance, carried out in Adzopé, showed a high presence of chloroquine resistance markers, while for SP a lower 
prevalence was detected. Since 2003, following the withdrawal of these antimalarials as first- and second-line drugs, respectively, the status of chloroquine and pyriméthamine-resistant parasite has not changed much in Adzopé with regard to the mutations affecting $d h f r-t s$ and pfcrt genes.

\section{ACKNOWLEDGEMENT}

The authors are very grateful to Drs M Adja, AL Ahou and NB Tchiekoi for assisting in the collection of $P$. falciparum samples in the study area. Thanks are also due to $\operatorname{Dr} A$ Mazabraud (Director of Research) who provided facilities for the PCR test in his laboratory (CNRS-UPR 3294 Bat.445, Université Paris Sud, 91405 Orsay Cedex, France).

\section{REFERENCES}

1. Kilama WL. Malaria vaccines in Africa. Acta Trop 2003; 88: 153-159.

2. Snow RW, Guerra CA, Noor AM, Myint HY, Hay SI. The global distribution of clinical episodes of Plasmodium falciparum malaria. Nature 2005; 434: 214-217.

3. Kahigwa E, Schellenberg D, Sanz S, Aponte JJ, Wigayi J, Mshinda $H$, Alonso P, Menendez C. Risk factors for presentation to hospital with severe anaemia in Tanzanian children: a casecontrol study. Trop Med Int Health 2002; 7: 823-830.

4. Ouma P, Parise ME, Hamel MJ, Ter Kuile FO, Otieno $K$, Ayisi JG, Kager PA, Steketee RW, Slutsker $L$, van Eijk $A M$. A randomized controlled trial of folate supplementation when treating malaria in pregnancy with sulfadoxine-pyrimethamine. PLoS Clin Trials 2006; 1: e28.

5. Triglia T, Cowman AF. Primary structure and expression of the dihydropteroate synthetase gene of Plasmodium falciparum. Proc Natl Acad Sci U S A 1994; 91: 7149-7153.

6. Talisuna AO, Nalunkuma-Kazibwe $A$, Langi $P$, Mutabingwa TK, Watkins WW, Van Marck $E$, Egwang TG, D'Alessandro U. Two mutations in dihydrofolate reductase combined with one in the dihydropteroate synthase gene predict sulphadoxine-pyrimethamine parasitological failure in Ugandan children with uncomplicated falciparum malaria. Infect Genet Evol 2004; 4: 321-327.

7. Djaman JA, Mazabraud A, Basco L. Sulfadoxinepyrimethamine susceptibilities and analysis of the dihydrofolate reductase and dihydropteroate synthase of Plasmodium falciparum isolates from Cote d'Ivoire. Ann Trop Med Parasitol 2007; 101: 103-112.

8. Laufer MK, Thesing PC, Eddington ND, Masonga $R$, Dzinjalamala FK, Takala SL, Taylor TE, Plowe CV. Return of chloroquine antimalarial efficacy in Malawi. N Engl J Med 2006; 355: 19591966.

9. Juliano JJ, Kwiek JJ, Cappell K, Mwapasa V, Meshnick SR. Minority-variant pfcrt K76T mutations and chloroquine resistance, Malawi. Emerg Infect Dis 2007; 13: 872-877.

10. Cohuet $S$, Bonnet $M$, Van Herp $M$, Van Overmeir $C$, D'Alessandro U, Guthmann JP. Short report: molecular markers associated with Plasmodium falciparum resistance to sulfadoxine-pyrimethamine in the Democratic Republic of Congo. Am J Trop Med Hyg 2006; 75: $152-154$

11. Djimde A, Doumbo OK, Cortese JF, Kayentao K, Doumbo S, Diourte $Y$, Dicko $A$, Su $X Z$, Nomura T, Fidock DA et al. A molecular marker for chloroquine-resistant falciparum malaria. N Engl J Med 2001; 344: 257-263.

12. Kublin JG, Cortese JF, Njunju EM, Mukadam RA, Wirima JJ, Kazembe PN, Djimdé AA, Kouriba $B$, Taylor TE, Plowe CV. Reemergence of chloroquine-sensitive Plasmodium falciparum malaria after cessation of chloroquine use in Malawi. J Infect Dis 2003; 187: 1870-1875.

13. Myers RL, Burghoff RL, English DW, Wenzel $A Z$, Harvey MA. Evaluation of Isocode and other novel collection matrices as nucleic acid storage and processing devices for clinical samples. Poster reprint presented at 49th AACC Annual Meetting, July 20-24th, 1997, Atlanta, GA.\# 774.

14. Bwijo B, Kaneko A, Takechi M, Zungu IL, Moriyama Y, Lum JK, Tsukahara T, Mita T, Takahashi N, Bergqvist $Y$, et al. High prevalence of quintuple mutant dhps/dhfr genes in Plasmodium falciparum infections seven years after introduction of sulfadoxine and pyrimethamine as first line treatment in Malawi. Acta Trop 2003; 85: 363-373.

15. Djaman J, Ahibo H, Yapi FH, Bla BK, Ouattara L, YavoW, N'guessan J-D, Yapo A, Mazabraud A. Molecular Monitoring of Falciparaum Malaria Isolates in Côte d'Ivoire: Genetic Markers (dhfr-ts, dhps, pfcrt, pfmdr-1) for Antimalarial-Drugs Resistance. Eur $J \mathrm{Sci}$ Research 2010; 40: 461-470.

16. Figueiredo $P$, Benchimol C, Lopes $D$, Bernardino L, $E$ do Rosário $V$, Varanda $L$, Nogueira $F$. Prevalence of pfmdr1, pfcrt, pfdhfr and pfdhps mutations associated with drug resistance, in Luanda, Angola. Malar J 2008; 7: 236.

17. Bridges DJ, Molyneux M, Nkhoma S. Low level genotypic chloroquine resistance near Malawi's northern border with Tanzania. Trop Med Int Health 2009; 14: 1093-1096.

18. Wichmann $O$, Jelinek $T$, Peyerl-Hoffman $G$, Muehleberger N, Grousch MP, Gascon J, Matteelli A, Hatz C, Laferl $H$, Schulze $M$ et al. 


\section{Ouattara et al}

and the European Network on Surveillance of Imported Infectious Diseases. Molecular surveillance of the antifolate-resistant mutation $1164 \mathrm{~L}$ in imported african isolates of Plasmodium falciparum in Europe: sentinel data from TropNetEurop. Malaria J 2003, 2: 17.

19. Farnert $A$, Tengstam $K$, Palme IB, Bronner $U$, Lebbad $M$, Swedberg G, Bjorkman $A$. Polyclonal Plasmodium falciparum malaria in travelers and selection of antifolate mutations after proguanil prophylaxis. Am J Trop Med Hyg 2002; 66: 487-491.

20. Ochong EO, van den Broek IV, Keus K, Nzila A. Short report: association between chloroquine and amodiaquine resistance and allelic variation in the Plasmodium falciparum multiple drug resistance 1 gene and the chloroquine resistance transporter gene in isolates from the upper Nile in southern Sudan. Am J Trop Med Hyg 2003; 69: 184187.

21. Cox-Singh J, Zakaria R, Abdullah MS, Rahman $H A$, Nagappan $S$, Singh $B$. Short report: differences in dihydrofolate reductase but not dihydropteroate synthase alleles in Plasmodium falciparum isolates from geographically distinct areas in Malaysia. Am J Trop Med Hyg 2001; 64: 28-31.

22. van den Broek IV, van der Wardt S, Talukder L, Chakma S, Brockman A, Nair S, Anderson TC. Drug resistance in Plasmodium falciparum from the Chittagong Hill Tracts, Bangladesh. Trop Med Int Health 2004; 9: 680-687. 